\section{Listeria monocytogenes empyema in an HIV infected patient}

\author{
Anna Marron, Beatriz Rosón, \\ Jordi Mascaró, Jordi Carratalà
}

\begin{abstract}
Listeriosis in HIV infected patients is uncommon and usually presents as meningitis or bacteraemia. Pleural fluid infections caused by this organism are extremely rare. A case is described of empyema caused by Listeria monocytogenes in an HIV infected patient that was successfully treated with medical treatment only.
\end{abstract}

(Thorax 1997;52:745-746)

Keywords: Listeria monocytogenes, empyema, HIV.

Listeria monocytogenes is a Gram positive motile bacillus that mainly affects subjects with defects in cell mediated immunity, pregnant women, or neonates. Listeriosis usually presents as meningitis or bacteraemia, although other manifestations such as septic arthritis, brain abscess, infective endocarditis, endophthalmitis, and hepatitis have been described. ${ }^{1}$ Pleural fluid infections caused by $L$ monocytogenes are extremely rare. ${ }^{23}$ We report a case of $L$ monocytogenes empyema in an HIV infected patient.

\section{Case report}

A 33 year old woman, a former intravenous drug abuser who was HIV infected and a heavy drinker, presented to our hospital with a 48 hour history of fever, non-productive cough, pleuritic left pain, and shortness of breath. Two years before admission biopsy proven liver cirrhosis was documented. She had had several previous admissions for ascites, spontaneous bacterial peritonitis, or spontaneous bacteraemia. No HIV related pathology was known. She was receiving zidovudine $500 \mathrm{mg}$ daily and prophylaxis with aerosolised pentamidine. On examination she appeared acutely ill, with a respiratory rate of $32 / \mathrm{min}$ and a temperature of $38.5^{\circ} \mathrm{C}$. The liver and the spleen were enlarged but no ascites was detected. The findings of the chest examination were consistent with a left pleural effusion. Physical examination was otherwise normal. Initial laboratory tests revealed a white cell count of $5.2 \times 10^{3} / \mathrm{ml}$ (with $82 \%$ neutrophils, $10 \%$ lymphocytes, $6 \%$ monocytes, and $2 \%$ band forms), a CD4 T lymphocyte count of $41 / \mathrm{mm}^{3}$ $(8 \%$, normal range $39-52 \%)$, haemoglobin of
$8 \mathrm{mmol} / \mathrm{l}$, and platelets of $84 \times 10^{3} / \mu \mathrm{l}$. An arterial blood sample while breathing room air had a $\mathrm{pH}$ of $7.43, \mathrm{PCO}_{2}$ of $4.4 \mathrm{kPa}$, and $\mathrm{Po}_{2}$ of $12.8 \mathrm{kPa}$. Chest radiography demonstrated a left pleural effusion. Thoracocentesis was performed yielding a cloudy yellowish fluid. Pleural fluid analysis revealed an exudate with a $\mathrm{pH}$ of $7.3,35 \mathrm{~g} / 1$ protein, $4.9 \mathrm{mmol} / 1$ glucose, $840 \mathrm{IU} / 1$ lactate dehydrogenase $(\mathrm{LDH})$ (plasma glucose $5.6 \mathrm{mmol} / \mathrm{l}$; LDH $420 \mathrm{IU} / 1$, normal range $60-250 \mathrm{IU} / \mathrm{l})$, and 1400 cells (83\% polymorphonuclear leucocytes). Gram staining showed abundant polymorphonuclear cells but no bacteria. Listeria monocytogenes serotype IV was isolated from pleural fluid and blood.

The initial treatment with intravenous ceftriaxone $1 \mathrm{~g}$ daily was then discontinued and intravenous ampicillin $2 \mathrm{~g}$ every four hours plus gentamicin $200 \mathrm{mg}$ daily were administered for 14 days. After four days of antibiotic therapy both blood and pleural fluid cultures were negative and she was discharged on oral trimethoprim-sulphamethoxazole. One year later the patient remains alive and no other listerial infections have been documented.

\section{Discussion}

A population based study has shown that patients with AIDS have an increased risk of developing invasive listeriosis of up to 145 times that of the general population. ${ }^{4}$ However, listeriosis has rarely been described in HIV infected patients, and most of the reported cases presented as meningitis and bacteraemia. $^{5-7}$ To our knowledge only one case of pleural fluid infection with $L$ monocytogenes in an HIV infected patient has been previously reported. ${ }^{3}$ It should be noted that, as in our case, that patient also had chronic liver disease, a condition that could have been an additional predisposing factor for invasive listeriosis. In addition, our patient was receiving inhaled pentamidine instead of trimethoprim-sulphamethoxazole which may also have contributed to development of infection. Haematogenous spread and secondary seeding of the pleura seems to be the route of infection in most cases of pleural fluid infection caused by $L$ monocytogenes, as we think occurred in our patient. ${ }^{2}$ Conversely, the HIV infected patient previously described ${ }^{3}$ had pneumonia and developed an effusion probably as a parapneumonic process since blood cultures yielded no bacteria. Neither ascites nor abdominal pain was present, although the association of listerial empyema with spontaneous bacterial peritonitis has also been recognised. ${ }^{8}$ High doses of ampicillin or penicillin, together with an aminoglycoside, is the treatment of choice for listeriosis, principally when poor prognostic indicators are present. ${ }^{9}$ Trimethoprim-sulphamethoxazole, commonly given to AIDS patients for prophylaxis of Pneumocystis carinii infection, is also an effective therapy for listeria 
infections. ${ }^{9}$ Whether or not chest tube drainage in $L$ monocytogenes empyema is necessary remains unclear. However, a complete resolution of the empyema was obtained in both previously mentioned cases with medical treatment only.

We therefore believe that $L$ monocytogenes should be considered in the differential diagnosis of empyema in patients with HIV infection.

1 Niemen RE, Lorber B. Listeriosis in adults: a changing pattern. Report of eight cases and review of the literature, 1968-1978. Rev Infect Dis 1980;2:207-27.

2 Mazzulli T, Salid IE. Pleural fluid infection caused by Listeria monocytogenes: case report and review. Rev Infect Dis 1991; 13:564-70
3 Domingo P, Serra J, Sambeat MA, Ausina V. Pneumonia due to Listeria monocytogenes. Clin Infect Dis 1992;14:787-9. 4 Jurado RL, Farley MM, Pereira E, Harvey RC, Schuchat A Wenger JD, et al. Increased risk of meningitis and bacteremia due to Listeria monocytogenes in patients with human inmunodeficiency virus infection. Clin Infect Dis 1993;17 $224-7$.

5 Berenguer J, Solera J, Diaz MD, Moreno S, López-Herce JA, Bouza E. Listeriosis in patients infected with human immunodeficiency virus. Rev Infect Dis 1991;13:115-9.

6 Decker CF, Simon GL, DiGioia RA, Tuazon CV. Listeria monocytogenes in patients with AIDS: report of five cases and review. Rev Infect Dis 1991;13:413-7.

7 Mascola L, Lieb L, Chiu J, Fannin SL, Linnan MJ. Listeriosis: an uncommon opportunstic infection in patients with acquired immunodeficiency syndrome. A report of five cases and a review of the literature. Am f Med 1988;84: $162-4$.

8 Simpson JF, Leddy JP, Hare JD. Listeriosis complicating lymphoma. Report of four cases and interpretative review of pathogenic factors. Am f Med 1967;43:39-49.

9 Jones EM, MacGowan AP. Antimicrobial chemotherapy of human infection due to Listeria monocytogenes. Eur f Clin Microbiol Infect Dis 1995;14:165-75.

Thorax 1997;52:746-748

\section{Occupational asthma in an isothiazolinone manufacturing plant}

\author{
S J Bourke, R P Convery, S C Stenton, \\ R M Malcolm, * D J Hendrick
}

\begin{abstract}
A chemical plant operator developed asthma five months after starting work in an isothiazolinone manufacturing plant. He described symptoms of late asthmatic reactions after work with isothiazolinone. Airway responsiveness to methacholine improved tenfold when he was removed from the plant for 18 days. A workplace challenge study then resulted in a deterioration in airway responsiveness to its earlier level and in progressive falls in forced expiratory volume in one second $\left(F_{E V}\right)$ over three days at work compared with control days, indicating statistically significant late asthmatic reactions of increasing severity.

(Thorax 1997;52:746-748)
\end{abstract}

Keywords: occupational asthma, biocides, isothiazolinone.

Isothiazolinones are being used increasingly as broad spectrum biocides in various water systems and in products such as paper, paints, and cosmetics. ${ }^{12}$ In some circumstances they have been used as substitutes for formaldehyde and glutaraldehyde which are known to cause asthma. ${ }^{3}$ There have been many reports of isothiazolinones causing occupational dermatitis but evidence of asthma due to isothiazolinones is lacking. ${ }^{45}$ We describe the occurrence of asthma in an isothiazolinone manufacturing plant, and a workplace challenge study which suggested it was occupational in origin. We think it likely that this was the result of sensitisation to isothiazolinone.

\section{Case report}

A 53 year old chemical plant operator developed asthma five months after starting work in an isothiazolinone manufacturing plant. $\mathrm{He}$ had no previous history of asthma or atopic disease and he was an ex-smoker. His job involved the filling of containers with various formulations of isothiazolinones in aqueous solution, including a combination of 5-chloro2-methyl-4-isothiazolin-3-one and 2-methyl-4isothiazolin-3-one. This was performed in an enclosed booth fitted with an extractor, but as he frequently opened the door of the booth to replace containers there was potential exposure to low concentrations of airborne isothiazolinone, which is weakly volatile. $\mathrm{He}$ described symptoms of cough and wheeze, which occurred towards the end of his working shifts, persisted into the evenings after work, and often disturbed his sleep at night. He was diagnosed as having asthma by his general practitioner and was prescribed salbutamol and beclomethasone inhalers. He had noticed that his symptoms were related to his work and he had tried to reduce his exposure, but he remained at the same job over the next five years until he was referred for assessment. His forced expiratory volume in one second $\left(\mathrm{FEV}_{1}\right)$ was 3.91 litres (109\% predicted) and his forced vital capacity (FVC) was 5.69 litres (127\% predicted) while taking salbutamol and beclomethasone, and he had moderate airway responsiveness to methacholine with a provoking dose responsible for a $20 \%$ fall in $\mathrm{FEV}_{1}\left(\mathrm{PD}_{20}\right)$ of $230 \mu \mathrm{g}$. Skin tests for atopy gave negative results. His history was suggestive of occupationally provoked late asthmatic reactions and a workplace challenge study was undertaken.

\section{WORKPLACE CHALLENGE STUDY}

His asthma treatment was stopped, he was withdrawn from the workplace for 18 days, and then re-exposed to his normal work environment. Spirometric tests were performed hourly from 07.00 hours to 17.00 hours on three control days away from work, and hourly from 07.00 hours to 23.00 hours on a fourth control day. He then returned to his normal job, working a 07.00 hours to 15.00 hours shift, 


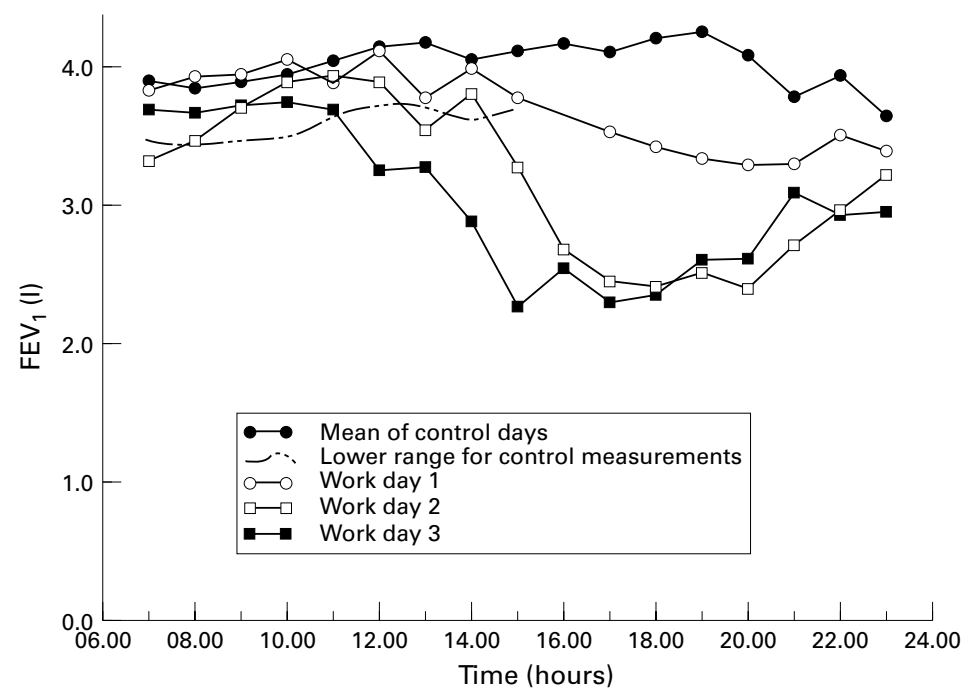

Figure 1 Serial measurements of FEV $V_{1}$ during workplace challenge study.

and spirometric testing was performed hourly from 07.00 hours to 23.00 hours on three consecutive work days. He spent each shift as usual filling containers with isothiazolinone formulations containing a mixture of 5-chloro2-methyl-4-isothiazolin-3-one and 2-methyl-4isothiazolin-3-one. This was performed as an enclosed process within the booth but he opened the door of the booth frequently throughout the shift, as usual, putting containers in place and screwing on their lids.

On each of the three study days at work he developed nasal irritation, cough, wheeze and chest tightness starting 4-6 hours into the shift and persisting into the evening with sleep disturbance at night. Figure 1 shows the mean $\mathrm{FEV}_{1}$ values for the control days 1-3 (07.0017.00 hours), a "lower boundary" equivalent to a $95 \%$ confidence limit, and evening values (18.00-23.00 hours) for control day 4. Superimposed are the plots for the three days at work. Each crosses the "lower boundary" at a progressively earlier time and with progressively greater strength, indicating statistically significant late asthmatic reactions of increasing severity. ${ }^{6}$ Airway responsiveness to methacholine was measured on four occasions. On his last day at work before the study the $\mathrm{PD}_{20}$ was $115 \mu \mathrm{g}$; on days 10 and 18 away from work it improved sequentially to $267 \mu \mathrm{g}$ and $1107 \mu \mathrm{g}$, but three days after his return to work it had deteriorated to $110 \mu \mathrm{g}$.

Air monitoring in the manufacturing plant had showned low but measurable levels of isothiazolinone of $0.01-0.3 \mathrm{mg} / \mathrm{m}^{3}$. These were well within the control limits set internally by the manufacturer in order to avoid possible irritant effects. Out of a total of 20 workers in the plant two others developed symptoms of asthma after beginning employment. Both then changed the nature of their work so that the possibility of ongoing exposure to isothiazolinone was much reduced. One recovered fully and the other, a maintenance technician, improved. However, the maintenance technician was subsequently involved in an accident which resulted in facial and eye contact with dissolved isothiazolinone. This caused a brief period of conjunctival inflammation but not worsening asthma.

\section{Discussion}

The clinical history of the chemical plant operator was strongly suggestive of occupational asthma in that he had developed asthma de novo after a short latent interval of employment, with a close relationship between symptoms and periods at work. The workplace challenge study provided objective evidence of statistically significant late asthmatic reactions occurring at progressively earlier times and with progressively greater magnitude on each of the three successive days during which he worked with isothiazolinone. ${ }^{7}$ This suggests increasing levels of airway responsiveness during the study period.

Changes in airway responsiveness associated with emergent or resolving occupational asthma (or with inhalation provocation tests) may be rapid and dramatic, though such changes in asthmatic activity are rarely seen in other circumstances. ${ }^{7}$ The significance of changes of $\mathrm{PD}_{20}$ can be assessed when population samples undergo two methacholine tests and the coefficient of repeatability (CR) is calculated. Estimates for CR using our dosimeter method for methacholine tests have given values in the range of $2-3$, indicating that an increase in $\mathrm{PD}_{20}$ to threefold or a decrease to one third identifies a statistically significant change. ${ }^{8}$ During the period of investigation in this case the $\mathrm{PD}_{20}$ values increased approximately tenfold over the 18 day period away from work and then fell to almost exactly the initial value on re-exposure to the work environment for three days. The importance of being able to identify significant changes in airway responsiveness in association with inhalation provocation tests is that the test agent or environment can be shown to be a potential inducer of asthma, not merely a provoker of asthmatic attacks.

The workplace challenge study in this case consequently provided strong evidence for a diagnosis of occupational asthma, and the suspicion that two of 20 fellow workers had similarly developed asthma provides additional support. The nature of the operator's work, the known sensitising properties of isothiazolinone in the skin, and the confirmed presence of respirable isothiazolinone (albeit in low concentrations) in the work environment suggest that isothiazolinone was the cause. We think this is likely, and we assume that isothiazolinone, like many reactive chemicals of low molecular weight, acts as a hapten through immunological mechanisms. This is thought to explain its effect in causing dermatitis. ${ }^{9}$ Our investigations do not prove a causal relationship, however, and there is a need for specific inhalation provocation tests to provide definitive conclusions.

Sodium metabisulphite is used in the plant to inactivate isothiazolinone following accidental spillages, and this substance has been reported to cause immediate asthmatic reactions fol- 
lowing inhalation..$^{10}$ It has consequently been implicated as a cause of occupational asthma, but it has not been shown to cause late asthmatic reactions nor to cause increases in airway responsiveness, and it is unclear whether the operator we describe could have been exposed to airborne metabisulphite during the three days of the workplace challenge study. We would consequently regard this as a much less plausible cause for his occupational asthma.

Isothiazolinone biocides are being used increasingly in a number of industries - for example, the manufacture of cosmetics, shampoos, synthetic fibre, and paper products. Their sterilising properties are used also in humidifier and air conditioning systems. Dermatitis has been reported in consumers as a result of topical contact in both occupational and domestic settings, ${ }^{459}$ so the potential risk for the development of asthma may be widespread. The opportunity for respirable exposure may, however, be limited. Furthermore, isothiazolinones are generally encountered in much greater dilution by consumers than by workers engaged in their manufacture.

\footnotetext{
1 Hunziker N. The isothiazolinone story. Dermatology 1992; 184:85-6.

Leino T. Superallergens in preservatives. Work Health Safety Institute of Occupational Health Finland, 1994:9.

3 Gannon PFG, Bright P, Campbell M, O'Hickey SP, Burge PS. Occupational asthma due to glutaraldehyde and formaldehyde in endoscopy and $x$-ray departments. Thorax 1995;50:156-9.

4 Hunziker N, Pasche F, Bircher A, Bruckner-Tuderman L, Hunziker T, Schmid P, et al. Sensitization to the $L$, Hunziker $T$, Schide. $P$, et al. Sensitization to the isothizolinone biocide. Report of the Swiss contact dermatitis research gro

5 Valsecchi R, Leghissa P, Piazzolla S, Cainelli T, Seghizzi P. Occupational dermatitis from isothiazolinones in nylon production. Dermatology 1993;187:109-11.

6 Stenton SC, Avery AJ, Walters EH, Hendrick DJ. Statistical approaches to the identification of late asthmatic reactions. Eur Respir F 1994;7:806-12.

7 Convery RP, Bourke SJ, Stenton SC, Hendrick DJ. Marked and rapid changes in airway responsiveness in early occupational asthma. Eur Respir f 1995;8(Suppl 19):194s.

8 Beach JR, Young CL, Avery AJ, Stenton SC, Dennis JH, Walters $\mathrm{EH}$, et al. Measurement of airway responsiveness to methacholine: relative importance of the precision of drug delivery and the method of assessing response. Thorax 1993:48:239-43.

9 Moss JN. Reconciling clinical data with risk: the kathon biocide story. Occup Med 1994;9:113-9.

10 Malo JL, Cartier A, Desjardins A. Occupational asthma caused by dry metabisulphite. Thorax 1995;50:585-6.
}

\section{Regression of polyvinylchloride polymer pneumoconiosis}

\author{
Neil W White, Rodney I Ehrlich
}

\begin{abstract}
A 35 year old man heavily exposed to polyvinylchloride (PVC) polymer dust developed dyspnoea and a mild restrictive lung disorder consistent with PVC pneumoconiosis. Clinical and radiological abnormalities cleared on removal from exposure, suggesting that in its early stages PVC pneumoconiosis is reversible.

(Thorax 1997;52:748-749)
\end{abstract}

Respiratory Clinic Department of Medicine, University of Cape Town, Groote Schuur Hospital, South Africa 7925 $\mathrm{N}$ W White

Department of Community Health University of Cape Town,

South Africa R I Ehrlich

Correspondence to: Dr N W White.

Received 7 October 1994 Returned to authors

13 December 1994

Revised version received

29 August 1996

Accepted for publication

25 September 1996
Keywords: polyvinylchloride, pneumoconiosis, lung disease.

\section{Case report}

In November 1991 a 35 year old plastics factory employee presented with sore throat, blocked nose, chest tightness, and pleuritic chest pains. Physical examination and chest radiography were normal. Pulmonary function test values were at the lower limit of normal (table 1). ${ }^{1}$ Serial peak flows recorded over two weeks showed no variability, and no diagnosis was made.

In July 1993 he returned with persistent sore throat, nasal and eye irritation, occasional dyspnoea, and a non-productive cough which had been present for several months. His effort tolerance had declined and he was no longer able to play soccer. A detailed occupational history established that he had worked since 1985 primarily with a fine polyvinylchloride (PVC) powder, manually loading hoppers under very dusty conditions using only a simple mask as respiratory protection. A visit to the factory confirmed his description; there was no local exhaust ventilation and general ventilation was inadequate. Various pigments and other chemicals were added to the PVC, but he was not involved in this later part of the process.

He had never smoked, had no domestic bird exposure, no tuberculosis contact, nor any history suggestive of allergy or atopy. Examination showed sparse fine crackles over the left lower zone. Full blood count, differential count, international normalised ratio, and serum levels of angiotensin converting enzyme (ACE) were normal.

Pulmonary function testing showed a reduction of more than $600 \mathrm{ml}$ in volumes and a slight decline in gas transfer, indicating mild restriction (table 1 ). The chest radiograph was unchanged. A high resolution computed tomographic (HRCT) scan of the chest showed a fine nodular pattern in both lower lobes, more extensive on the left, with no pleural or other pathology seen (fig 1). There was no lymphadenopathy nor other signs to suggest sarcoidosis such as nodularity along the bronchovascular markings.

Transbronchial biopsy specimens obtained by fibreoptic bronchoscopy from the left lower lobe showed focal areas of interstitial fibrosis. Conspicuous fibrin deposition was noted within the interstitium. There was a general paucity of inflammatory cells, but the bronchial wall showed a moderate infiltrate of chronic inflammatory cells. The basement membrane was mildly thickened. No granulomatous changes were seen. No exogenous material was 
Table 1 Serial changes in pulmonary function

\begin{tabular}{lcccccc}
\hline & $\begin{array}{l}\text { November } \\
1991\end{array}$ & $\begin{array}{l}\text { fune } \\
1993\end{array}$ & $\begin{array}{l}\text { November } \\
1993\end{array}$ & $\begin{array}{l}\text { Fune } \\
1994\end{array}$ & $\begin{array}{l}\text { fuly } \\
1995\end{array}$ & $\begin{array}{l}\text { Mean (SD) } \\
\text { predicted }\end{array}$ \\
\hline $\mathrm{FEV}_{1}(\mathrm{ml})$ & 2440 & 1800 & 2120 & 2360 & 2400 & $3270(840)$ \\
$\mathrm{FVC}(\mathrm{ml})$ & 3050 & 2370 & 2750 & 2990 & 3170 & $3850(1000)$ \\
$\mathrm{FEV}$ & $80 \mathrm{FVC}(\%)$ & 76 & 77 & 79 & 76 & 85 \\
$\mathrm{TLCO}(\mathrm{mmol} \mathrm{CO} / \mathrm{kPa} / \mathrm{min})$ & 78.6 & 68.7 & & 84.3 & 80.4 & $82.8(20.7)$ \\
$\mathrm{KCO}(\mathrm{mmol} \mathrm{CO} / \mathrm{kPa} / \mathrm{min} / \mathrm{l})$ & 20.7 & 19.8 & & 21.3 & 21.3 & $18.3(3.9)$ \\
\hline
\end{tabular}

$\mathrm{FEV}_{1}=$ forced expiratory volume in one second; $\mathrm{FVC}=$ forced vital capacity; TLCO=single breath carbon monoxide diffusing capacity; $\mathrm{KCO}=$ TLCO/alveolar volume.

identified in the macrophages by scanning electron microscopy.

In November 1993, three months after removal from exposure to PVC powder, improvement in the pulmonary function tests was noted (table 1). By June 1994 he was asymptomatic, with lung function values close to those at his first visit in 1991. On repeat HRCT scanning the nodularity present a year before was much less evident.

\section{Discussion}

Pulmonary reaction to polyvinylchloride polymer dust has been documented in epidemiological $^{2-5}$ and histological studies. ${ }^{6-8}$ Clinically, PVC pneumoconiosis is a diagnosis of exclusion in the context of appropriate exposure. Sarcoidosis was the main alternative diagnosis here, but the absence of extrapulmonary clinical features, normal serum levels of ACE, the absence of non-caseating granulomas on transbronchial biopsy specimens, and no characteristic features on the HRCT scan effectively excluded this possibility. Furthermore, the natural history of his complaint and the absence of corresponding positive features were thought to exclude tuberculosis and connective tissue disorders. No risk factors for an extrinsic alveolitis were identified. The only environmental modification that occurred prior to his improvement was his removal from exposure to PVC dust.

Histological examination showed focal areas of fibrosis and conspicuous fibrin in the interstitium, but not some of the features documented in heavily dusted experimental animals ${ }^{6}$ and in case reports of workers with respiratory disease following heavy exposure to PVC who

Figure 1 HRCT scan of chest showing small regular nodules in both lower lobes.

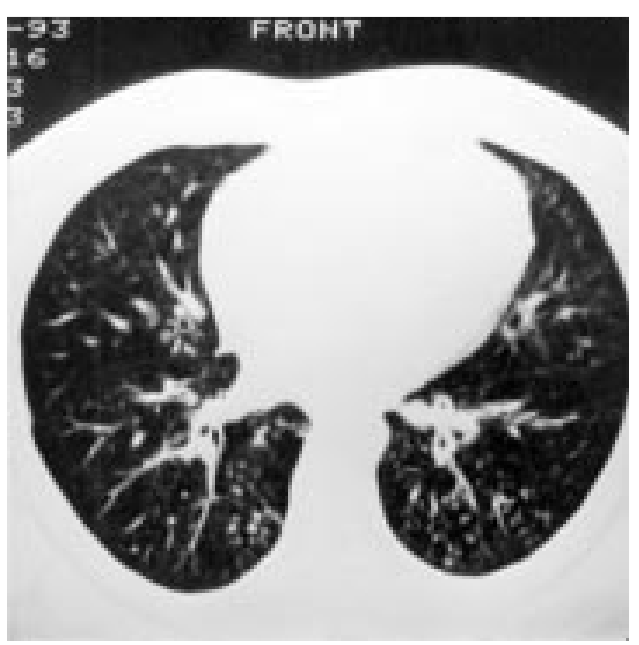

$\operatorname{died}^{7}$ or from whom lung biopsy samples were taken. ${ }^{6}$ Intracellular foreign particles have been seen in macrophages by scanning electron microscopy of specimens from heavily dusted animals. ${ }^{6}$ The other case report in English which described a lung biopsy specimen found that the nodules represented a histiocytic infiltrate in a collagen matrix. ${ }^{6}$ These histiocytes/ macrophages have clear vacuoles with a few multinuclear giant cells also present.

The non-specific abnormalities in the airways and parenchyma seen in our case could reflect limited biopsy tissue. Alternatively, we may have documented an earlier stage or milder form of PVC pneumoconiosis, where macrophage mediated fibrosis is limited and largely reversible.

Our patient developed mild ventilatory restriction and slightly reduced gas transfer. Respiratory symptoms, pulmonary function changes, and abnormalities on the chest radiograph have been documented in cross sectional studies of workers employed in PVC production and fabrication. In two studies ${ }^{34}$ exposure to PVC dust was associated with mild functional restriction and small rounded or irregular opacities of low profusion radiologically. A third study ${ }^{5}$ found PVC exposure to be associated with airflow limitation, while a fourth documented both patterns of spirometric abnormality. ${ }^{2}$

The epidemiologic studies did not describe the natural history of the cases of PVC pneumoconiosis identified. We could find no published description suggesting that PVC pneumoconiosis might regress. This case suggests that in its early stages or after a relatively short exposure, PVC pneumoconiosis is largely reversible. Further longitudinal studies are needed before we fully understand the natural history of PVC pneumoconiosis.

1 Quanjer $\mathrm{PhH}$, ed. Standardised lung function testing: report of the working party. Bull Eur Physiopathol Respir 1983; 19(Suppl 5):195-208.

2 Lilis R, Anderson H, Miller A, Selikoff IJ. Pulmonary changes among vinylchloride polymerization workers. Chest 1976 69S:299-302.

3 Mastrangelo G, Manno M, Arcer G, Bartolussi GB, Gemignani C, Saladino G, et al. Polyvinylchloride pneumoconiosis: epidemiological study of exposed workers. $\mathcal{F} \mathrm{Occup}$ Med 1979;21:540-2.

4 Soutar CA, Copland LH, Thornley PE, Hurley JF, Ottery J, Adams WGF, et al. Epidemiological study of respiratory disease in workers exposed to polyvinylchloride dust. Thorax 1980;35:644-52.

5 Baser ME, Tockmar MS, Kennedy TP. Pulmonary function and respiratory symptoms in polyvinylchloride fabrication and respiratory symptoms in polyvinylchloride
workers. Am Rev Respir Dis 1985;131:203-8.

6 Arnauld A, Pommier De Santi P, Garbe L, Payman H, Charpin J. Polyvinylchloride pneumoconiosis. Thorax Charpin J. Polyvinylchloride pneumoconiosis. Thorax

7 Szende B, Lapis K, Nemes A, Pinter A. Pneumoconiosis caused by the inhalation of polyvinylchloride dust. Med Lav 1970;61:433-6.

8 Forongia N, Spinozzola A, Bucharelli A. Lesioni pulmonari sperimentali da inalazione prolungata di PVC in ambiente di lavoro. Med Lav 1974;65:321-42. 